\title{
Barriers to the provision of optimal care to dying patients in hospital: a cross-sectional study of nurses' perceptions
}

\author{
AUTHORS \\ JAN SHEPHERD ${ }^{1}$ \\ AMY WALLER ${ }^{1}$ \\ ROB SANSON-FISHER ${ }^{1,2}$ \\ KATHERINE CLARK ${ }^{3,4}$ \\ JEAN BALL ${ }^{2}$
}

\section{CORRESPONDING AUTHOR}

JAN SHEPHERD School of Medicine and Public Health, University of Newcastle, Hunter Medical Research Institute, Callaghan, New South Wales, Australia, 2308. Email: Jan.Shepherd@uon.edu.au
1 School of Medicine and Public Health, University of Newcastle, University Drive, Callaghan, NSW, Australia

2 Hunter Medical Research Institute, New Lambton Heights, NSW, Australia

3 Department of Palliative Care, Northern Sydney Local Health District, St Leonards, NSW, Australia

4 Northern Clinical School, The University of Sydney, St Leonards, NSW, Australia

\section{ABSTRACT}

Objectives: To examine in a sample of nurses working in acute-care wards, self-reported perceptions of the: 1) patient; family; nurse; doctor; and health system-related barriers to the provision of optimal end-of-life care to people who are dying in hospital; and 2) five barriers which, if removed, would lead to the greatest improvements in hospital-based end-of-life care.

Background: Nurses play a central role in caring for dying patients and can offer a unique perspective about the factors that impact the quality of end-oflife care delivered in hospitals.

Study design and methods: Two hundred and fifteen registered and enrolled nurses from three metropolitan and three rural hospitals across three health services completed a questionnaire-based, cross-sectional study between April 2016 and June 2017.

Results: Nurses perceive that doctors continue to treat for too long (79\% ranked as a large barrier); families have unrealistic expectations about a patient's prognosis (73\%); junior doctors are unwilling to alter the decision of senior doctors (67\%); doctors do not adequately explain the dying process (66\%); and doctors have inadequate training in end-of-life care $(66 \%)$. Nurses indicated that doctors reducing the length of active treatment and families having a more realistic expectation about life-expectancy would lead to the greatest improvement in end-oflife care in hospitals.

Discussion: In this study of nurses working in a wide range of acute care settings across rural and metropolitan locations, substantial barriers to the provision of high-quality end-of-life care were perceived across all facets of healthcare provision. Important barriers included the continuation of potentially futile treatment, inadequacy of symptom control, and poor communication between doctors, patients and their families.

Conclusion: Nurses perceive a range of patient; family; provider; and health system-related challenges to the provision of optimal end-of-life care in hospital. Findings highlight potential areas for improvement as part of a coordinated approach to optimising the provision of end-of-life care in 
hospitals. Future goals should include larger-scale, longitudinal studies across various states and territories to inform the development of interventions that can help to address the identified gaps in service provision.

\section{Implications for research, policy, and practice:} This study has highlighted the need to involve all stakeholders when designing interventions to improve end-of-life care. Nurses can provide valuable insight into the factors that can make the greatest impact in improving care provision. It suggests that the provision of high-quality end-oflife care in hospitals is complex, and that there is substantial overlap between items nurses perceive to be barriers in each of the five domains of care provision. To achieve sustainable improvement in the quality of end-of-life care provided in hospitals, a multi-factorial, and collegial, approach to designing interventions will be needed.
What is already known about the topic?

- End-of-life care is increasingly being provided in hospital settings.

- Nurses are an important source of information and support for dying patients and their families.

- Few studies have explored nurses' perceptions of the barriers to the provision of high-quality end-oflife care across all domains of healthcare provision.

What this paper adds:

- Important barriers include continuation of potentially futile treatment, adequacy of symptom control, and poor communication between doctors, patients, and their families.

- Findings can support the design of more effective intervention strategies to mitigate identified barriers and achieve improvements in the quality of end-of-life care delivered in hospital.

Keywords: nurses; terminal care; acute care; Australia; communication; barriers

\section{INTRODUCTION}

End-of-life care is defined as care that helps people who have been diagnosed with an advanced, terminal illness to live as well as possible until they die. ${ }^{1}$ Although as many as two-thirds of the population would prefer to receive care at home in the last year of life, a significant proportion of people will receive hospital-based care in the last year of life. ${ }^{4}$ As families become smaller, and more geographically diverse, there may be fewer people available to care for dying family members (that is, patients expected to die within the next few days or weeks) in the home environment; or else those who are available may lack the ability to provide the care that is needed. ${ }^{2}$ An ageing population, combined with limited availability of formal services to facilitate end-of-life care outside the hospital environment are other contributing factors., 4 In addition, as people approach the end of their lives, some will choose to receive care in a hospital.,5, Consequently, it can be expected that there will be increasing strain placed on a health system that continues to expose dying patients and their families to potentially unwanted interventions at the end of life.7 Such interventions can be invasive and aggressive, and there is little evidence that they alter outcomes; rather, they frequently reduce the quality of patients' remaining time and leads to more complicated bereavement outcomes for family members. ${ }^{8}$ Difficulty predicting the prognosis of dying patients has been cited as one reason for continuing to provide active treatment, even though many conditions tend to follow a predictable trajectory. ${ }^{9}$
Achieving improvements in the quality of hospital-based end-of-life care has been prioritised in national and international policy and practice documents..$^{10,11}$ In Australia, the National Consensus Statement guidelines were released in 2015 in an effort to standardise/guide end-of-life care delivery in Australian acute care settings. ${ }^{12}$ These guidelines describe 10 essential elements for high-quality end-of-life care, and address areas of direct healthcare provision in hospitals, including patient-centred communication, teamwork and coordination of care; as well as organisational characteristics such as ongoing training programs and the provision of support for clinical staff who are caring for dying patients. The provision of end-of-life care in hospitals is a recent addition to the National Safety and Quality Health Service Standards, with a requirement that end-of-life care meet the 10 essential elements outlined in the Consensus Statement. ${ }^{11}$ Though all Australian hospitals are required to be accredited to these standards, the implementation of end-of-life policies remains the responsibility of individual healthcare services, and there is some evidence to suggest that end-of-life care in hospitals continue to fall short of expectations. ${ }^{13}$ The provision of complex and invasive treatments at the end of life is common; and there is some doubt that patients and their families are fully informed about the potential benefits and risks of these treatments. ${ }^{14}$ The result can be an end-of-life experience that fails to meet the expectations of patients or families, leading to extended, complex bereavement outcomes. ${ }^{15}$ This can also have adverse long-term implications for those delivering care, as well as placing an increasing burden on the health system. ${ }^{13,14}$ 
Developing interventions that can lead to better end-oflife outcomes for patients dying in hospitals requires an understanding of the factors that impede the delivery of high-quality end-of-life care. However, interventions are frequently designed without formal analysis of these issues. ${ }^{13,16}$ Evaluations of complex interventions are also often undermined by problems that could have been identified before the initiation of a large-scale effectiveness study. ${ }^{17}$ Improving the effectiveness relies on attention to their design and feasibility. ${ }^{17}$

The pivotal role of doctors in designing treatment regimens may result in them bearing much of the perceived responsibility when care does not meet expectations. ${ }^{18}$ It is important to recognise that treatment plans may be designed on the basis of issues that arise in other domains of healthcare provision. For example, continuing treatment beyond what might reasonably be considered appropriate may, in fact, be driven by patient or family-related demands. A holistic examination of the factors that may influence endof-life care quality is essential if sustainable improvements are to be made. Such analysis should therefore include the perceptions of all key stakeholders in the provision of hospital-based end-of-life care. It should also encompass an analysis of the barriers across all domains of care; including individual patient, family, and healthcare provider domains, as well as institutional and system-related issues.

The relationships that can develop between nurses, their patients, and their families are unique and stem from the fact that nurses spend the bulk of their time at the bedside. ${ }^{19}$ Nurses are well-placed to understand the wishes and needs of their patients as they approach the end of their lives and, as such, can identify the issues that may impact delivery of care that meets those wishes. ${ }^{20}$ To date, much of the literature examining nurses' perceptions of hospital-based end-of-life care has been qualitative and while this provides depth of understanding, there is a need for methodologically rigorous quantitative studies. Other studies have been conducted in single institutions or wards; or have not examined the wide range of factors that may impact care delivery. ${ }^{20-22}$ Obtaining the views of a diverse group of nurses working in a range of wards, and several hospitals, about the factors that may impact delivery of end-of-life care is essential if interventions to improve end-of-life care delivery are to be effective.

\section{AIMS}

To examine the perceptions of general nurses working in acute care wards regarding:

1) patient, family; nurse; doctor; and health system-related barriers to the provision of optimal end-of-life care to people who are dying in hospital;

2) those barriers which, if removed, would make the greatest impact upon the provision of hospital-based end-of-life care.

\section{METHODS}

\section{DESIGN}

A cross-sectional survey of 215 registered and enrolled nurses working in acute care wards of three metropolitan and three rural hospitals from three health services in Australia.

\section{SURVEY DEVELOPMENT}

The survey was adapted from a cross-sectional patient survey used in previous studies of oncology outpatients, ${ }^{23}$ and older, hospitalised patients. ${ }^{24}$ This ensured that nurses were presented with barriers perceived by patients to be important for their own end-of-life experience. Steps in the development and establishment of face and content validity of the patient version have been described previously. ${ }^{23,24}$ Briefly, the survey included: (1) healthcare providers and consumers participating in 20-minute individual interviews to elicit their views and experiences in relation to end-of-life care; (2) review of potential items by an expert panel selected based on their role in caring for patients that represent common trajectories of decline that are eventually fatal and have the greatest probability of dying in hospital; 4 and (3) modifications and pilot testing of items with a convenience sample of 20 patients for acceptability, relevance and clarity, with refinements based on their feedback. A similar approach was used to adapt the patient version to the nurses' version of the survey administered in this study. It included: (1) qualitative interviews $(n=15)$ and a focus group $(\mathrm{n}=9)$ with nurses; (2) review of items by an expert panel comprised of behavioural scientists experienced in survey development, as well as clinicians with more than 20 years of experience, including a palliative care physician, a surgeon, an oncologist, a geriatrician, a nephrologist and nurses working in acute-care settings; and (3) pilot testing procedures with a small number of nurses. The final survey included items assessing: perceived barriers to delivering end-of-life care in hospitals; advance care planning knowledge and attitudes, ${ }^{25}$ and preferences for location of care ${ }^{26}$ however only the items examining nurses' perceived barriers to delivering end-of-life care in hospitals are presented here.

\section{PROCEDURE}

Eligible nurses on each ward were identified with the assistance of the Nurse Unit Manager and approached for consent by a member of the research team, who provided verbal and written information about the study. Completion of the survey was taken as consent. Participants completed an anonymous survey either during pre-scheduled in-service education sessions held on the ward during shift, or in the nurses' own time. Surveys were also placed in staff rooms of participating wards where nurses could access them if they wished to participate. Nurses could return their survey in a reply-paid envelope directly to the research team or seal it 
in an envelope and place it in a designated box on the ward to be collected by the research team. All nurses were advised that completion of the survey was voluntary. Evidence based strategies including an offer of providing feedback about the study results were used to maximise response to the invitation. ${ }^{27}$

\section{OUTCOME MEASURES}

Participants were presented with a list of 47 items, separated into five domains: patient-related barriers (7 items); familyrelated barriers ( 8 items); nurse-related barriers (11 items); doctor-related barriers (12 items); and health system-related barriers ( 9 items). Participants were asked to indicate the extent to which each item was a barrier to the provision of optimal end-of-life care on a four-point Likert scale ranging from large barrier to no barrier. Participants were then asked to list the five most important barriers which, if removed, would have the greatest impact on the delivery of end-of-life care. Responses were ranked on a scale from 1 to 5 , where 1 is the most important barrier and 5 is the least important barrier. Each item was given a score to indicate the ranking assigned by each nurse (a ranking of 1 was assigned a score of 5 ; a ranking of 2 was scored as 4 ; a ranking of 3 was scored as 3 ; a ranking of 4 was scored as a 2; and a ranking of 5 was scored as 1$)$.

\section{ASSOCIATE VARIABLES}

All associate variables were obtained via participant selfreport. Socio-demographic items included sex and age group (in 10-year increments). Clinical items included years of experience as a nurse, years worked in current hospital and current ward, number of shifts worked per week, and number of dying patients cared for in the past six months.

\section{STATISTICAL ANALYSIS}

Stata/IC 14 (StataCorp) was used for all analyses. Consent bias (age, sex and FTE status) was assessed by comparing responders to available Australian national data, using chi-squared analyses. Frequency data were used to describe barriers to the provision of optimal end-of-life care, including: the proportion of nurses who identified each item as a large/moderate/small/no barrier; and the proportion of nurses who ranked each large barrier as the most significant to the provision of optimal end-of-life care.

\section{ETHICS APPROVAL}

The University of Newcastle Human Research Ethics Committee (Ref: 16/02/17/5.03) and the ethics committees of the participating health services approved the study (LNRSSA/17/HNE/65; LNRSSA/17HNE/66 - 23/3/2016; o916-o86C $-10 / 10 / 2016)$.

\section{RESULTS}

\section{SAMPLE}

Participants' characteristics are presented in Table 1. Almost all participants had cared for at least one dying patient in the past six months; and $27 \%(\mathrm{n}=59)$ reported caring for 11 or more dying patients. The sample is representative of Australian national data in terms of nurses' gender and workload (FTE). There were significantly fewer respondents in the 51 years and over group compared to the Australian national data (30\% vs $39 \%, \mathrm{p}<0.01){ }^{28}$

Participating nurses identified a number of important barriers to the provision of optimal end-of-life care in each of the five domains. Table 2 presents the number and proportion of nurses who rated each item as either large, moderate, or small barrier, or no barrier at all, by individual domain. The most important issue overall, according to nurses in this study, was that doctors continue active treatment for too long $(79 \%$; $=168)$.

The importance of knowing patients' wishes for end-of-life care was clearly established, with two-thirds of nurses considering the lack of a documented Advance Care Plan to be a large barrier to the provision of optimal end-of-life care $(n=137)$. The other key patient-related issue according to nurses in this study was the provision of appropriate symptom management $(53 \% ; n=111)$. It was very important to nurses in this study that families have realistic expectations about the prognosis of their dying family member $(73 \% ; n=156)$, and that there is consensus among family members about the care their family member receives $(62 \% ; n=131)$. Nurses were concerned about their inability to provide sufficient pain relief to their patients, with half of all respondents ranking this as the largest barrier in the nurse domain $(51 \% ; n=110)$. When nurses felt that treatment plans did not align with the care that their patients and families wanted, this was considered a significant barrier to optimal end-of-life care $(47 \%$; $=100)$.

In the doctor domain, nurses identified a substantial number of areas where improvements could be made. Eighty percent considered that doctors continue treatment for too long $(n=168)$, and more than two-thirds were concerned that junior doctors were unwilling to alter decisions made by more senior doctors $(n=143)$. According to nurses in this study, substantial barriers exist in several other areas of medical care, including a lack of training in end-of-life care (66\%; $n=142$ ) and poor, or insufficient explanation of the dying process $(66 \% ; n=142)$ and delayed involvement of palliative care teams $(66 \% ; n=141)$. Avoidance of discussions with patients about end-of-life care was also a key concern of nurses in this study $(65 \% ; n=139)$.

Nurses were concerned that there was insufficient privacy for dying patients and their families $(57 \%$; $=122)$, and a lack of availability of specialist end-of-life care services was a key issue for nurses in this study $(55 \%$; $=119)$. 
TABLE 1: NURSE SOCIO-DEMOGRAPHIC CHARACTERISTICS AND CLINICAL EXPERTISE (N=215)

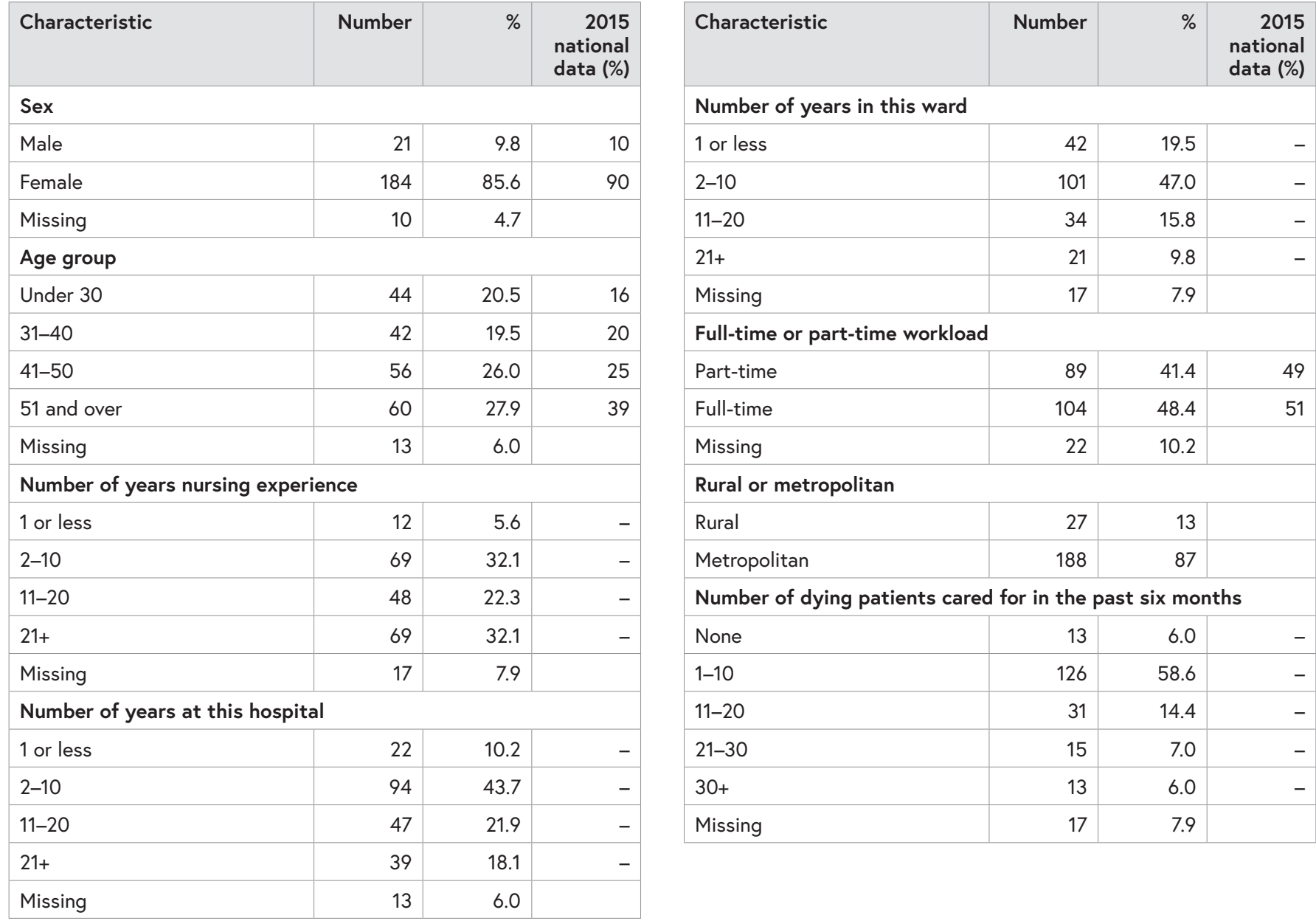

TABLE 2: NURSES' PERCEPTIONS OF THE BARRIERS TO PROVIDING OPTIMAL END-OF-LIFE CARE IN HOSPITALS, BY DOMAIN (BARRIERS RANKED IN ORDER FROM MOST TO LEAST SIGNIFICANT BARRIER IN EACH DOMAIN)

\begin{tabular}{|c|c|c|c|c|}
\hline Patient-related barriers & $\begin{array}{l}\text { Large } \\
\mathrm{N}(\%)\end{array}$ & $\begin{array}{r}\text { Moderate } \\
\mathrm{N}(\%)\end{array}$ & $\begin{array}{l}\text { Small } \\
\mathrm{N}(\%)\end{array}$ & $\begin{array}{l}\text { None } \\
\text { N (\%) }\end{array}$ \\
\hline Not having a documented Advance Care Plan & $137(64)$ & $54(25)$ & $21(10)$ & $2(1)$ \\
\hline Having unrelieved symptoms (e.g. pain/delirium/respiratory secretions) & $111(53)$ & $56(27)$ & $37(18)$ & $7(3)$ \\
\hline Being unable to communicate their wishes (e.g. reduced conscious level/aphasic) & $102(48)$ & $74(35)$ & $37(17)$ & $1(1)$ \\
\hline Having unrealistic expectations about prognosis & $97(46)$ & $76(36)$ & $35(17)$ & $3(1)$ \\
\hline Not understanding 'life-saving measures' & $97(45)$ & $82(38)$ & $33(15)$ & $2(1)$ \\
\hline Being afraid to ask questions & $74(35)$ & $73(34)$ & $52(25)$ & $13(6)$ \\
\hline Having cultural/religious/language barriers & $68(32)$ & $70(33)$ & $65(31)$ & $10(5)$ \\
\hline Family-related barriers & $\begin{array}{l}\text { Large } \\
\mathrm{N}(\%)\end{array}$ & $\begin{array}{r}\text { Moderate } \\
\mathrm{N}(\%)\end{array}$ & $\begin{array}{l}\text { Small } \\
\mathrm{N}(\%)\end{array}$ & $\begin{array}{l}\text { None } \\
\mathrm{N}(\%)\end{array}$ \\
\hline Disagreeing with each other about care & $131(62)$ & $60(28)$ & $20(9)$ & $2(1)$ \\
\hline Being distressed by unrelieved symptoms (e.g. pain/delirium/respiratory secretions) & $123(58)$ & $62(29)$ & $24(11)$ & $4(2)$ \\
\hline Not knowing the patient's wishes & $119(56)$ & $64(30)$ & $29(14)$ & $1(1)$ \\
\hline Not understanding 'life-saving measures' & $109(51)$ & $79(37)$ & $24(11)$ & $1(1)$ \\
\hline Not having a designated contact person & $86(40)$ & $73(34)$ & $45(21)$ & $10(5)$ \\
\hline Being afraid to ask questions & $66(31)$ & $84(39)$ & $52(24)$ & $12(6)$ \\
\hline Having cultural/religious/language barriers & $63(30)$ & $72(34)$ & $66(31)$ & $10(5)$ \\
\hline
\end{tabular}


TABLE 2: NURSES' PERCEPTIONS OF THE BARRIERS TO PROVIDING OPTIMAL END-OF-LIFE CARE IN HOSPITALS, BY DOMAIN (BARRIERS RANKED IN ORDER FROM MOST TO LEAST SIGNIFICANT BARRIER IN EACH DOMAIN) (CONTINUED)

\begin{tabular}{|c|c|c|c|c|}
\hline Nurse-related barriers & $\begin{array}{l}\text { Large } \\
\mathrm{N}(\%)\end{array}$ & $\begin{array}{r}\text { Moderate } \\
\mathrm{N}(\%)\end{array}$ & $\begin{array}{l}\text { Small } \\
\mathrm{N}(\%)\end{array}$ & $\begin{array}{l}\text { None } \\
\mathrm{N}(\%)\end{array}$ \\
\hline Being unable to provide sufficient pain relief & $110(51)$ & $71(33)$ & $30(14)$ & $3(1)$ \\
\hline Finding it difficult aligning patient/family needs with medical treatment plans & $100(47)$ & $74(34)$ & $38(18)$ & $3(1)$ \\
\hline Having inadequate training in end-of-life care & $95(45)$ & $69(33)$ & $39(18)$ & $9(4)$ \\
\hline Being too busy & $91(43)$ & $84(39)$ & $28(13)$ & $10(5)$ \\
\hline Feeling unable to discuss poor prognosis with patient/family & $87(41)$ & $64(30)$ & $48(23)$ & $14(7)$ \\
\hline Lacking involvement in end-of-life decision making & $76(36)$ & $72(34)$ & $54(25)$ & $12(6)$ \\
\hline Feeling inadequately supported as new graduates & $66(33)$ & $80(38)$ & $44(21)$ & $13(6)$ \\
\hline Equating palliative care with 'terminal care' & $66(31)$ & $81(38)$ & $45(21)$ & $22(10)$ \\
\hline Having limited continuity of care from day to day & $62(29)$ & $79(37)$ & $52(24)$ & $20(9)$ \\
\hline Finding it difficult to assess needs of patient/family & $59(28)$ & $89(42)$ & $60(28)$ & $6(3)$ \\
\hline Having cultural/religious barriers & $48(22)$ & $52(24)$ & $75(35)$ & $39(18)$ \\
\hline Doctor-related barriers & $\begin{array}{l}\text { Large } \\
\mathrm{N}(\%)\end{array}$ & $\begin{array}{r}\text { Moderate } \\
\mathrm{N}(\%)\end{array}$ & $\begin{array}{l}\text { Small } \\
\mathrm{N}(\%)\end{array}$ & $\begin{array}{l}\text { None } \\
\text { N (\%) }\end{array}$ \\
\hline Continuing treatment for too long & $168(79)$ & $34(16)$ & $12(6)$ & - \\
\hline Being unwilling to alter decisions of senior doctors & $143(67)$ & $55(26)$ & $14(7)$ & $2(1)$ \\
\hline Having inadequate training in end-of-life care & $142(66)$ & $54(25)$ & $16(7)$ & $3(1)$ \\
\hline Not adequately explaining the dying process & $142(66)$ & $59(28)$ & $13(6)$ & - \\
\hline Involving palliative care teams too late or not at all & $141(66)$ & $53(25)$ & $20(9)$ & $1(1)$ \\
\hline Avoiding discussions with patients & $139(65)$ & $58(27)$ & $15(7)$ & $3(1)$ \\
\hline Providing insufficient/inappropriate pain and symptom relief & $133(62)$ & $56(26)$ & $25(12)$ & $1(1)$ \\
\hline Not adhering to Advance Directives & $101(47)$ & $48(22)$ & $45(21)$ & $20(9)$ \\
\hline Finding it difficult to predict patient prognosis & $77(36)$ & $86(40)$ & $48(23)$ & $2(1)$ \\
\hline Having cultural/religious barriers & $59(27)$ & $51(24)$ & $76(35)$ & $29(14)$ \\
\hline Health system-related barriers & $\begin{array}{l}\text { Large } \\
\mathrm{N}(\%)\end{array}$ & $\begin{array}{r}\text { Moderate } \\
\mathrm{N}(\%)\end{array}$ & $\begin{array}{l}\text { Small } \\
\mathrm{N}(\%)\end{array}$ & $\begin{array}{l}\text { None } \\
\mathrm{N}(\%)\end{array}$ \\
\hline Insufficient private rooms/space (e.g. for dying patients, grieving families) & $122(57)$ & $61(28)$ & $24(11)$ & $8(4)$ \\
\hline A lack of specialist palliative care/end-of-life teams & $119(55)$ & $53(25)$ & $35(16)$ & $8(4)$ \\
\hline An inadequate system for documenting and communicating end-of-life wishes & $106(49)$ & $68(32)$ & $33(15)$ & $8(4)$ \\
\hline Poor access to existing Advance Directives & $95(44)$ & $72(33)$ & $39(18)$ & $9(4)$ \\
\hline Uncertainty about who is responsible for end-of-life decisions & $91(42)$ & $85(40)$ & $32(15)$ & $7(3)$ \\
\hline Insufficient registered and enrolled nurses & $83(39)$ & $67(31)$ & $44(21)$ & $21(10)$ \\
\hline A lack of continuity when patients are transferred between wards & $72(33)$ & $81(38)$ & $54(25)$ & $7(3)$ \\
\hline An inability to have family members stay overnight & $49(23)$ & $79(37)$ & $49(23)$ & $37(17)$ \\
\hline Limited visiting hours & 41 (19) & $50(23)$ & $48(22)$ & $76(35)$ \\
\hline
\end{tabular}

Note: percentages rounded to nearest whole number

Nurses identified the continuation of potentially futile treatment, inadequate symptom control, and poor communication between doctors, patients and their families as the five most significant barriers which, if removed, would lead to the greatest improvements in end-of-life care in hospitals (Table 3 ). 
TABLE 3: THE TOP FIVE BARRIERS WHICH, IF REMOVED, WOULD LEAD TO THE GREATEST IMPROVEMENTS IN EOL CARE - IN RANKED ORDER OF IMPORTANCE - TOTAL SCORE; (N)

\begin{tabular}{|c|c|c|c|c|c|c|}
\hline \multirow[t]{2}{*}{ Item } & \multicolumn{5}{|c|}{ Rankings - score (n) } & \multirow{2}{*}{$\begin{array}{l}\text { Overall } \\
\text { Score (n) }\end{array}$} \\
\hline & 1st & 2nd & 3rd & 4th & 5 th & \\
\hline Doctors continuing treatment for too long & $55(11)$ & $80(20)$ & $36(12)$ & $42(21)$ & $24(24)$ & $237(88)$ \\
\hline Patients not having a documented Advance Care Plan & $60(12)$ & $36(9)$ & $15(5)$ & $12(6)$ & $15(15)$ & $138(47)$ \\
\hline Doctors providing insufficient/inappropriate pain and symptom relief & $35(7)$ & $36(9)$ & $30(10)$ & $22(11)$ & $7(7)$ & $130(44)$ \\
\hline Doctors avoiding discussions with patients & $45(9)$ & $20(5)$ & $27(9)$ & $24(12)$ & $12(12)$ & $128(47)$ \\
\hline Doctors involving palliative care teams too late or not at all & $30(6)$ & $20(5)$ & $24(8)$ & $24(12)$ & $11(11)$ & $109(42)$ \\
\hline Doctors having inadequate training in end-of-life care & $30(6)$ & $24(6)$ & $24(8)$ & $12(6)$ & $9(9)$ & $99(35)$ \\
\hline A lack of specialist palliative care/end-of-life teams & $45(9)$ & $28(7)$ & $9(3)$ & $8(4)$ & $7(7)$ & $97(30)$ \\
\hline Families not knowing the patient's wishes & $30(6)$ & $24(6)$ & $15(5)$ & $16(8)$ & $3(3)$ & $88(28)$ \\
\hline Doctors not adequately explaining dying process & $35(7)$ & $20(5)$ & $21(7)$ & $8(4)$ & $2(2)$ & $86(25)$ \\
\hline Doctors being unwilling to alter decisions of senior doctors & $25(5)$ & $32(8)$ & $15(5)$ & $6(3)$ & $2(2)$ & $80(23)$ \\
\hline Doctors not adhering to Advance Directives & $15(3)$ & $40(10)$ & $6(2)$ & $10(5)$ & $3(3)$ & $74(23)$ \\
\hline Patients having unrelieved symptoms & - & $20(5)$ & $24(8)$ & $12(6)$ & $17(17)$ & $73(36)$ \\
\hline Nurses being too busy & $40(8)$ & $4(1)$ & $15(5)$ & $6(3)$ & $6(6)$ & $71(23)$ \\
\hline Families disagreeing with each other about care & $10(2)$ & $32(8)$ & $9(3)$ & $8(4)$ & $3(3)$ & $62(20)$ \\
\hline Insufficient private rooms/space & $20(4)$ & $16(4)$ & $12(4)$ & $6(3)$ & $7(7)$ & $61(22)$ \\
\hline Families being distressed by unrelieved symptoms & $5(1)$ & $32(8)$ & $15(5)$ & $8(4)$ & $1(1)$ & $61(19)$ \\
\hline Patients being unable to communicate their wishes & $20(4)$ & - & $24(8)$ & $12(6)$ & $3(3)$ & $59(21)$ \\
\hline Nurses having inadequate training in end-of-life care & $20(4)$ & $12(3)$ & $15(5)$ & $6(3)$ & $5(5)$ & $58(20)$ \\
\hline Nurses being unable to provide sufficient pain relief & $10(2)$ & $32(8)$ & $9(3)$ & - & $2(2)$ & $53(15)$ \\
\hline Patients having unrealistic expectations about prognosis & $10(2)$ & $8(2)$ & $15(5)$ & $12(6)$ & $7(7)$ & $52(22)$ \\
\hline Poor access to existing Advance Directives & $35(7)$ & $12(3)$ & - & $2(1)$ & - & $49(11)$ \\
\hline Doctors not involving nurses in treatment discussions & $15(3)$ & $8(2)$ & $15(5)$ & $6(3)$ & - & $44(13)$ \\
\hline Doctors being too busy & $10(2)$ & $16(4)$ & $9(3)$ & $4(2)$ & $3(3)$ & $42(14)$ \\
\hline Nurses lacking involvement in end-of-life decision making & $20(4)$ & $4(1)$ & $9(3)$ & $2(1)$ & $1(1)$ & $36(10)$ \\
\hline An inadequate system for documenting and communicating end-of-life wishes & $10(2)$ & $8(2)$ & $6(2)$ & $4(2)$ & - & $28(8)$ \\
\hline Insufficient registered and enrolled nurses & $5(1)$ & $12(3)$ & $3(1)$ & $4(2)$ & $2(2)$ & $26(9)$ \\
\hline Uncertainty about who is responsible for end-of-life decisions & $10(2)$ & - & $9(3)$ & $4(2)$ & $1(1)$ & $24(8)$ \\
\hline Patients not understanding 'life-saving measures' & $5(1)$ & $8(2)$ & $3(1)$ & $2(1)$ & $4(4)$ & $22(9)$ \\
\hline Family being afraid to ask questions & $15(3)$ & $4(1)$ & - & - & $1(1)$ & $20(5)$ \\
\hline An inability to have family members stay overnight & $5(1)$ & $4(1)$ & $6(2)$ & $2(1)$ & $1(1)$ & $18(6)$ \\
\hline Families not understanding 'life-saving measures' & $5(1)$ & $4(1)$ & $3(1)$ & $2(1)$ & $1(1)$ & $15(5)$ \\
\hline A lack of continuity when patients are transferred between wards & $5(1)$ & - & $9(3)$ & - & $1(1)$ & $15(5)$ \\
\hline Families not having a designated contact person & $10(2)$ & $4(1)$ & - & - & $1(1)$ & $15(4)$ \\
\hline Nurses feeling unable to discuss poor prognosis with patient/family & $5(1)$ & - & $6(2)$ & $2(1)$ & $1(1)$ & $14(5)$ \\
\hline Nurses equating palliative care with 'terminal care' & $5(1)$ & - & $6(2)$ & - & - & $11(3)$ \\
\hline Patients having cultural/religious barriers & $5(1)$ & $4(1)$ & - & - & $1(1)$ & $10(3)$ \\
\hline Patients being afraid to ask questions & - & $4(1)$ & $6(2)$ & - & - & $10(3)$ \\
\hline Nurses having cultural/religious barriers & - & $8(2)$ & - & - & - & $8(2)$ \\
\hline Doctors finding it difficult to predict patient prognosis & - & - & $3(1)$ & $2(1)$ & - & $5(2)$ \\
\hline A lack of continuity when patients are transferred between wards & $5(1)$ & - & - & - & - & $5(1)$ \\
\hline Doctors having cultural/religious barriers & - & - & - & - & $1(1)$ & $1(1)$ \\
\hline Families having cultural/religious barriers & - & - & - & - & - & - \\
\hline Nurses feeling inadequately supported as new graduates & - & - & - & - & - & - \\
\hline Nurses finding it difficult to assess needs of patient/family & - & - & - & - & - & - \\
\hline Limited visiting hours & - & - & - & - & - & - \\
\hline
\end{tabular}




\section{DISCUSSION}

In this study of nurses working in a wide range of acute care settings across rural and metropolitan locations, their perceptions of the patient; family; provider; and health system-related challenges to the provision of optimal end-of-life care in hospitals were identified. Substantial barriers to the provision of high-quality end-of-life care were perceived across all facets of healthcare provision. Nurses in this study considered that important barriers included the continuation of potentially futile treatment, inadequacy of symptom control, and poor communication between doctors, patients and their families. Findings highlight potential areas for improvement as part of a coordinated approach to optimising the provision of end-of-life care in hospitals.

Doctors continuing treatment for too long was perceived to be a barrier to the provision of high-quality end-of-life care by the largest proportion of nurses in this study (40\% reported it as one of the five most important barriers). This result is consistent with much of the literature reporting that many patients receive care that is variously described as futile or non-beneficial at the end of their lives. ${ }^{29}$ Such care is consistently reported to result in sub-optimal outcomes for patients and their families, distress for those providing that care, and place an unnecessary burden on an already stretched healthcare system. ${ }^{13,14,30}$ This study identified a number of factors within other domains that can impact on the provision of unwanted invasive treatments at the end of life. When patients do not have a documented Advance Care Plan, or when family members do not know the patient's wishes, it can be difficult for doctors to provide care that is consistent with the patient's wishes. Equally, when doctors avoid discussions with patients or provide insufficient information about the potential consequences of invasive treatments, patients and their families cannot make informed decisions about those treatments; including their impact on the patient's prognosis. Several of these factors were also identified by a significant proportion of nurses as large barriers to the provision of optimal end-of-life care.

Nurses place a substantial value on effective symptom management at the end of life, ${ }^{26}$ a view that may be shared by patients and their family members. ${ }^{11,32}$ The provision of insufficient or inappropriate pain relief was endorsed by the fourth highest proportion of nurses as a large barrier to the provision of optimal end-of-life care. There is widespread agreement that when end-of-life care is supported by palliative care teams, symptom management is improved. . $2,33^{2}$ However, in the system domain the availability of specialist palliative care teams and designated palliative care beds were endorsed by the sixth and eighth highest proportion of nurses as a large barrier to the provision of optimal end-oflife care in hospitals, suggesting that nurses recognise the potential for palliative care interventions to improve end- of-life care outcomes. Historically, specialist palliative care is generally associated with a diagnosis of cancer, meaning that the acknowledged improvements in end-of-life outcomes are often denied to patients who have a non-cancer related terminal diagnosis. ${ }^{34}$ The relative lack of these services both in hospital settings and in the community further limits the potential for widespread use of palliative care interventions for dying patients. ${ }^{35}$ It should be noted that many patients will experience improved end-of-life outcomes when care is shifted from curative to palliative under the guidance of generalist palliative principles, meaning that not all patients actually require specialist palliative care services. ${ }^{36}$ It is essential, then, that all doctors and nurses are equipped with the skills to provide this care and that they are supported by ongoing education programs. ${ }^{36}$ Central to this issue is the need for well-developed communication and interactional skills. ${ }^{37}$ This is not a novel concept; the value of incorporating communication skills in undergraduate medical education has long been acknowledged. ${ }^{38}$ Though there has been substantial focus on the importance of such skills in the years since, novice doctors and nurses continue to report feeling under-prepared to care for dying patients and their families. ${ }^{39,40}$ Efforts to improve the preparedness of doctors and nurses to provide high-quality end-of-life care should be supported.

In the patient domain, two-thirds of nurses considered not having a documented Advance Care Plan to be a large barrier to the provision of optimal end-of-life care. This was the most significant barrier according to nurses in this study. Advance planning practices encompass far more than the documentation of wishes, so there is a need to examine the extent to which dying patients have communicated their wishes with both their families and their treating teams, and the manner in which that information is provided. Many patients are unwilling to initiate discussions about their wishes as they approach the end of their lives, so providing opportunities for patients to communicate this information is critical. ${ }^{41}$ When family members are aware of the dying patient's wishes (either through an Advance Care Plan or as a result of informal end-of-life discussions) this can also reduce conflict among family members and subsequently improve the end-of-life experience for both of them and the patient. ${ }^{42}$

Approximately half of the nurses in this study considered being unable to provide sufficient pain relief and finding it difficult to align patient and family needs with medical treatment plans to be the two largest barriers in the nurse domain. This result reflects the value nurses place on adequate symptom management and the normalisation of the dying process. ${ }^{26}$ When nurses are unable to provide care that aligns with the wishes of the patient and their family, they can experience ethical and moral dilemmas and an associated increase in work-related stress. 43,44 
Results in the doctor domain were relatively equivocal, with 10 of the 12 items being ranked as a large barrier by more than half of all nurses. More than two-thirds of nurses considered six items in the doctor domain to be a large barrier to the provision of optimal end-of-life care in hospitals. This result is consistent with previous studies, ${ }^{45-47}$ and is, perhaps, unsurprising as doctors bear the primary responsibility for the management of patients approaching the end of their lives. Strategies to improve outcomes in this domain may have a substantial impact on outcomes within other domains. For example, improvements in doctors' ability to communicate bad news or adequately explain treatment options may lead to an improvement in the expectations of patients and their families, and subsequently an end-of-life experience that more closely aligns with their wishes.

Consistent with much of the existing literature, a lack of private rooms and quiet spaces for patients and their families was considered to be a significant barrier to the provision of high-quality end-of-life care, and it was the top system-related barrier. It is widely accepted that the hospital environment is busy and often noisy, affording patients and their families little opportunity to grieve in private. ${ }^{15,26}$ Acknowledging the importance of maintaining dignity at the end of life and providing a quiet place for families to grieve, a number of projects are seeking novel solutions to this problem.

The Irish Hospice Foundation Design and Dignity program transforms little used areas of the hospital into dedicated quiet spaces where families can meet with their doctors, or simply have a quiet moment away from the busy ward environment. ${ }^{48}$ Building on the global Compassionate Communities concept, ${ }^{49}$ several local healthcare districts are designing hospital-based end-of-life care programs that optimise the hospital environment for dying patients and their families. ${ }^{\circ 0}$ Further efforts to create more 'home-like' environments and equip staff with the skills to provide sensitive and compassionate end-of-life care are to be encouraged.

Religious and/or language issues were not considered to be a barrier to the provision of optimal end-of-life care in the hospitals engaged in this work. Similar results have been reported in previous studies examining nurses' perceptions of barriers to the provision of optimal end-of-life care..$^{11}$ Religious and/or spiritual education is limited in many undergraduate nursing programs and nurses often report feeling underprepared to deal with this role, ${ }^{52}$ so it is perhaps surprising that nurses in this study did not perceive it to be a barrier to providing optimal end-of-life.

\section{STRENGTHS AND LIMITATIONS}

The inclusion of the views of both rural and metropolitan nurses from six hospitals, and three healthcare services increases the generalisability of the results. Within Australia, legislative requirements for Advance Planning documentation vary from state to state and territory, and this study described the views of nurses from one state. As such, the generalisability of results to hospitals in other regions should be made with caution. The results of this study represent the perceptions of hospital-based nurses at a single time-point and should be studied in conjunction with the views of other stakeholders; e.g. patients/families/doctors. The survey-based design did not permit the inclusion of qualitative data. In addition, it is possible that nurses' responses may differ based on their individual hospital circumstances and experiences. A small number of nurses reported caring for no dying patients in the preceding six months and their responses may not be representative of those who have cared for more dying patients.

\section{CONCLUSION}

Nurses perceive a range of patient; family; provider; and health system-related challenges to the provision of optimal end-of-life care in hospital. The most significant barriers related to the continuation of treatment, adequacy of symptom control, and communication between doctors, patients and their families. To achieve sustainable improvement in the quality of end-of-life care provided in hospitals, a multi-factorial approach to designing interventions will be needed. Future goals should include larger-scale, longitudinal studies across various states and territories to inform the development of interventions that can help to address the identified gaps in service provision.

\section{IMPLICATIONS FOR RESEARCH, POLICY, AND PRACTICE}

This study has highlighted the complex nature of hospitalbased end-of-life care. There is a need to consider the way in which elements in one domain of the end-of-life experience can impact the barriers seen in each of the other domains. To achieve sustainable improvement in the quality of end-of-life care provided in hospitals, a multi-factorial, multi-disciplinary, and collegial approach to designing interventions will be needed, with consideration given to elements from each domain and involving a range of stakeholders. The design of such interventions should consider the findings of existing descriptive studies gathered from other stakeholders (patients, families, and other clinicians). Additionally, there is a need to equip health services with the necessary infrastructure and funding to translate successful large-scale trials into everyday practice. 


\section{DECLARATIONS}

Funding, authorship and acknowledgements: The authors would also like to acknowledge infrastructure support from Hunter Medical Research Institute (HMRI) and funding from the Australian Research Council DECRA (150101262); and the University of Newcastle/Hunter Cancer Research Alliance PhD scholarship. L/Prof Rob Sanson-Fisher, Dr Amy Waller and Ms Jan Shepherd conceived the study and questionnaire, and contributed to data acquisition, analysis and interpretation of study findings. Professor Katherine Clark and Ms Jean Ball contributed to analysis and interpretation of study findings. All authors have read and approved the final version to be published and agree to be accountable for this work. The authors would like to acknowledge the time and effort provided by the nurses who took part in this research, as without their assistance this work would not be possible.

Declaration of conflicts of interest: The authors declare there are no conflicts of interest.

\section{REFERENCES}

1. Palliative Care Australia. Health system reform and care at the end of life. A guidance document. 2010. ACT, Australia.

2. Horsfall D, Leonard R, Noonan K and Rosenberg J. Working together-apart: exploring the relationships between formal and informal care networks for people dying at home. Prog Palliat Care 2013; 21: 331-336.

3. World Health Organization. Global atlas of palliative care at the end of life. 2017.

4. Swerissen H, Duckett S and Farmer J. Dying well. Report no. 1925015610, 2014. Grattan Institute, Melbourne.

5. Aoun SM, Breen LJ and Howting D. The support needs of terminally ill people living alone at home: a narrative review. Health Psychol Behav Med 2014; 2: 951-969.

6. Gomes B, Calanzani N, Gysels M, Hall S and Higginson IJ. Heterogeneity and changes in preferences for dying at home: a systematic review. BMC Palliat Care 2013; 12: 7.

7. To T, Greene A, Agar M and Currow D. A point prevalence survey of hospital inpatients to define the proportion with palliation as the primary goal of care and the need for specialist palliative care. Intern Med J 2011; 41: 430-433.

8. Cardona-Morrell M, Kim JC, Brabrand M, Gallego-Luxan B and Hillman K. What is inappropriate hospital use for elderly people near the end of life? A systematic review. Eur J Intern Med 2017; 42: 39-50.

9. Lynn J and Adamson DM. Living well at the end of life. Adapting health care to serious chronic illness in old age. Santa Monica, CA: RAND Health, 2003.

10. Australian Commission on Safety and Quality in Health Care. Safety and quality of end-of-life care in acute hospitals; a background paper. 2013. Sydney, Australia: ACSQHC.

11. Australian Commission on Safety and Quality in Health Care. National Safety and Quality Health Service Standards. 2017. Sydney, Australia: ACSQHC.

12. Australian Commission on Safety and Quality in Health Care. National Consensus Statement: essential elements for safe and high-quality end-of-life care. 2015. Sydney, Australia: ACSQHC.
13. Clark K, Byfieldt N, Green M, Saul P, Lack J and Philips JL. Dying in two acute hospitals: would usual care meet Australian national clinical standards? Aust Health Rev 2014; 38: 223-229.

14. Heyland D, Cook D, Bagshaw SM, et al. The very elderly admitted to ICU: a quality finish? Crit Care Med 2015; 43: 1352-1360.

15. Donnelly S, Prizeman G, Coimín D, Korn B and Hynes G. Voices that matter: end-of-life care in two acute hospitals from the perspective of bereaved relatives. BMC Palliat Care 2018; 17: 117.

16. Chan R, Webster J, Phillips J and Currow D. The withdrawal of the Liverpool Care Pathway in the United Kingdom: what are the implications for Australia? Med J Aust 2014; 200: 572-573

17. Hallingberg $B$ and et al. Exploratory studies to decide whether and how to proceed with full-scale evaluations of public health interventions: a systematic review. Pilot Feasibility Stud 2018; 4: 104. DOI: 10.1186/s40814-018-0290-8.

18. Wong AK, Carey SE and Kenner DJ. Can hospital doctors provide quality palliative care informed by end-of-life care legislation: An Australian perspective. Archives of Medicine and Health Sciences 2021; 9: 50.

19. Dillworth J, Dickson VV, Mueller A, Shuluk J, Yoon HW and Capezuti E. Nurses' perspectives: hospitalized older patients and end-of-life decision-making. Nurs Crit Care 2016; 21: e1-e11.

20. Adams JA, Bailey DE, Anderson RA and Docherty SL. Nursing roles and strategies in end-of-life decision making in acute care: a systematic review of the literature. Nurs Res Pract 2011.

21. Stevens $K$. The impact of evidence-based practice in nursing and the next big ideas. Online J Issues Nurs 2013; 18.

22. Meier EA, Gallegos JV, Thomas LPM, Depp CA, Irwin SA and Jeste DV. Defining a good death (successful dying): literature review and a call for research and public dialogue. Am J Geriatr Psychiatry 2016; 24: 261-271.

23. Waller A, Sanson-Fisher R, Zdenkowski N, Douglas C, Hall A and Walsh $\mathrm{J}$. The right place at the right time: medical oncology outpatients' perceptions of location of end-of-life care. J Nat Compr Canc Netw 2018; 16: 35-41.

24. Waller A, Sanson-Fisher R, Nair BR and Evans T. Preferences for end-of-life care and decision making among older and seriously ill inpatients: a cross-sectional study. J Pain Symptom Manage 2019; 59: 187-196.

25. Shepherd J, Waller A, Sanson-Fisher R, Clark K and Ball J. Knowledge of, and participation in, advance care planning: a cross-sectional study of acute and critical care nurses' perceptions. Int J Nurs Stud 2018; 86: 74-81.

26. Shepherd J, Waller A, Sanson-Fisher R, Clark K and Ball J. Where would acute care nurses prefer to receive end-of-life care? A cross-sectional survey. Int J Nurs Stud 2020; 109.

27. Edwards PJ, Roberts I, Clarke MJ, et al. Methods to increase response to postal and electronic questionnaires Cochrane Database of Systematic Reviews 2009; 3.

28. Australian Institute of Health and Welfare. Nursing and midwifery workforce 2015. 2015. Canberra, Australia: AlHW.

29. Cardona-Morrell M, Kim J, Turner RM, Anstey M, Mitchell IA and Hillman K. Non-beneficial treatments in hospital at the end of life: a systematic review on extent of the problem. Int J Qual Health Care 2016; 28: 456-469.

30. Wright AA, Zhang B, Keating NL, Weeks JC and Prigerson HG. Associations between palliative chemotherapy and adult cancer patients' end of life care and place of death: prospective cohort study. BMJ 2014; 348. 
31. Virdun C, Luckett T, Lorenz K and Phillips J. National quality indicators and policies from 15 countries leading in adult endof-life care: a systematic environmental scan. BMJ Support Palliat Care 2018; 8: 145-154.

32. Clark K. Care at the very end-of-life: dying cancer patients and their chosen family's needs. Cancers 2017; 9: 11.

33. Diop MS, Rudolph JL, Zimmerman KM, Richter MA and Skarf LM. Palliative care interventions for patients with heart failure: a systematic review and meta-analysis. J Palliat Med 2017; 20: 84-92.

34. Rosenwax L, Spilsbury K, McNamara BA and Semmens JB. A retrospective population based cohort study of access to specialist palliative care in the last year of life: who is still missing out a decade on? BMC Palliat Care 2016; 15: 46.

35. Carey ML, Zucca AC, Freund MA, Bryant J, Herrmann A and Roberts BJ. Systematic review of barriers and enablers to the delivery of palliative care by primary care practitioners. Palliat Med 2019; 33: 1131-1145.

36. Nevin M, Hynes G and Smith V. Healthcare providers' views and experiences of non-specialist palliative care in hospitals: A qualitative systematic review and thematic synthesis. Palliat Med 2020; 34: 605-618.

37. Sanson-Fisher R, Hobden B, Carey M, Mackenzie L, Hyde L and Shepherd J. Interactional skills training in undergraduate medical education: ten principles for guiding future research. BMC Med Educ 2019; 19: 1-7.

38. Sanson-Fisher R and Maguire P. Should skills in communicating with patients be taught in medical schools? Lancet 1980; 316: 523-526.

39. Croxon L, Deravin $L$ and Anderson J. Dealing with end of life-New graduated nurse experiences. J Clin Nurs 2018; 27: 337-344.

40. Cheng DR and Teh A. Palliative care in Australian medical student education. Med Teach 2014; 36: 82-83.

41. Bernacki RE and Block SD. Communication about serious illness care goals: a review and synthesis of best practices. JAMA Int Med 2014; 174: 1994-2003.

42. Detering KM, Hancock AD, Reade MC and Silvester W. The impact of advance care planning on end of life care in elderly patients: randomised controlled trial. BMJ 2010; 340: c1345.

43. Borhani F, Mohammadi S and Roshanzadeh M. Moral distress and perception of futile care in intensive care nurses. J Med Ethics Hist Med 2015; 8.

44. Austin CL, Saylor R and Finley PJ. Moral distress in physicians and nurses: Impact on professional quality of life and turnover. Psychol Trauma 2017; 9: 399.

45. Periyakoil VS, Neri E and Kraemer H. Patient-reported barriers to high-quality, end-of-life care: a multiethnic, multilingual, mixed-methods study. J Palliat Med 2016; 19: 373-379.

46. Omar Daw Hussin E, Wong LP, Chong MC and Subramanian P. Nurses' perceptions of barriers and facilitators and their associations with the quality of end-of-life care. J Clin Nurs 2018; 27: e688-e702.

47. Beckstrand RL, Hadley KH, Luthy KE and Macintosh JL. Critical care nurses' suggestions to improve end-of-life care obstacles: minimal change over 17 years. Dimens Crit Care Nurs 2017; 36: 264-270.

48. Irish Hospice Foundation. Hospice friendly hospitals programme: design and dignity, https://hospicefoundation.ie/ healthcare-programmes/hospice-friendly-hospitals/design-anddignity/ (2020, accessed 16 September 2020).
49. Kellehear A. Compassionate communities: end-of-life care as everyone's responsibility. QJM 2013; 106: 1071-1075.

50. Zadeh RS, Eshelman P, Setla J, Kennedy L, Hon E and Basara A. Environmental design for end-of-life care: An integrative review on improving the quality of life and managing symptoms for patients in institutional settings. Journal of pain and symptom management 2018; 55: 1018-1034.

51. Beckstrand RL, Collette J, Callister L and Luthy KE. Oncology nurses' obstacles and supportive behaviors in end-of-life care: providing vital family care. Oncol Nurs Forum 2012; 39.

52. Cooper KL and Chang E. Undergraduate nurse students' perspectives of spiritual care education in an Australian context. Nurse Educ Today 2016; 44: 74-78. 